\title{
Monogeneans of the catfish Pimelodus blochii Valenciennes (Siluriformes: Pimelodidae) from the Brazilian Amazon, with a description of a new species of Ameloblastella Kritsky, Mendoza-Franco \& Scholz, 2000 (Monogenea: Dactylogyridae)
}

\author{
Luciano P. Negreiros • Marcos Tavares-Dias • Felipe B. Pereira $₫$
}

Received: 17 November 2018/Accepted: 6 May 2019/Published online: 13 May 2019

(C) Springer Nature B.V. 2019

\begin{abstract}
Ameloblastella amazonica n. sp. (Monogenea: Dactylogyridae) collected on the gills of Pimelodus blochii Valenciennes (Siluriformes: Pimelodidae) from Rivers Acre and Iaco, State of Acre (Brazil) is described. The new species differs from the congeners mainly by the morphology of the dorsal bar, i.e. slightly U-shaped bearing a posteriorly directed flap, arising from the anterior edge of its middle third. The most morphologically similar congeners, A. paranaensis (França, Isaac, Pavanelli \&
\end{abstract}

This article was registered in the Official Register of Zoological Nomenclature (ZooBank) as F2D721FF-84A7-4459-9CA3AD03B85E5EB5. This article was published as an Online First article on the online publication date shown on this page. The article should be cited by using the doi number. This is the Version of Record.

This article is part of the Topical Collection Monogenea.

Electronic supplementary material The online version of this article (https://doi.org/10.1007/s11230-019-09862-y) contains supplementary material, which is available to authorized users.

\section{P. Negreiros}

Programa de Pós-Graduação em Biodiversidade e Biotecnologia (PPG-BIONORTE), Universidade Federal do Amapá Campus Universitário, Macapá,

AP 68903-419, Brazil

M. Tavares-Dias

Embrapa Amapá, Macapá, AP 68903-419, Brazil
Takemoto, 2003) and A. satoi Monteiro, Kritsky \& Brasil-Sato, 2010, resemble A. amazonica n. sp. regarding the general structure of the copulatory complex; however, besides other features, they also differ from the new species because their hooks are similar in size ( $v s$ hooks with three different sizes). In addition to the dorsal bar lacking a flap, A. amazonica n. sp. can be differentiated from all congeners based on the combination of the following features: size of hooks (one or two different sizes), shape of the dorsal bar (other than slightly U-shaped), anchor points largely passing the level of superficial root ( $v s$ not or slightly passing it), number of MCO rings (other than 3-4) and structure of the articulation between the MCO base and the accessory piece (other than thick, medium-sized, smooth and tubular). Demidospermus leptosynophallus Kritsky \& Gutierrez, 1998 and Scleroductus yuncensi Jara \& Cone, 1989 were also found infesting $P$. blochii, both representing new host and locality records.

\footnotetext{
F. B. Pereira ( $\square)$

Programa de Pós-Graduação em Biologia Animal, Instituto de Biociências (INBIO), Universidade Federal de Mato Grosso do Sul (UFMS), Campo Grande,

MS 79070-900, Brazil

e-mail: felipebisaggiop@hotmail.com
} 


\section{Introduction}

The Amazon basin represents one of the most diverse biomes for fish species in the world (Nelson et al., 2016). In this sense, these organisms considered as hosts, may harbour a rich fauna of parasites including several taxa (Hechinger \& Lafferty, 2005; Poulin, 2014). However, the biodiversity of these parasites is underestimated as is the case of the Monogenea (see Mendoza-Palmero et al., 2015).

Dactylogyridae Bychowsky, 1933 represents a large and speciose family within the Monogenea and is composed by highly host-specific parasites (Boeger \& Vianna, 2006; Cohen et al., 2013). The dactylogyrid genera Amelloblastella Kritsky, Mendoza-Franco \& Scholz, 2000, Demidospermus Suriano, 1983 and Scleroductus Jara \& Cone, 1989 include parasites mostly infesting catfish (Siluriformes) from South and Central America (Mendoza-Franco \& Scholz, 2009; Kritsky et al., 2013; Mendoza-Franco et al., 2016). Currently, Amelloblastella and Demidospermus, both parasitic on the gills, comprise 10 and 30 valid species, respectively (Mendoza-Franco \& Scholz, 2009; Mendoza-Franco et al., 2016; Acosta et al., 2017; Franceschini et al., 2018). Scleroductus, which parasitises the body surface mainly from pimelodid fishes (Pimelodidae) in South America, allocates only three valid species (Kritsky et al., 2013).

Although a large number of taxonomic studies have been dedicated to the above-mentioned genera, their biodiversity potential is enormous (Mendoza-Palmero et al., 2015) and should be explored, since the taxonomic knowledge represents the basis for understanding further biological issues (Padial et al., 2010; Poulin, 2014). During parasitological surveys on Pimelodus blochii Valenciennes (Pimelodidae), collected in two rivers from the Brazilian Amazon, State of Acre, specimens of monogeneans were found on the gills of the fish. Detailed morphological examination revealed that these parasites belong to three different species of three different genera, one of which we assigned to Ameloblastella, as a new species described herein.

\section{Materials and methods}

One hundred and sixty specimens of $P$. blochii were collected with the aid of local fisherman in the upper
River Acre, near the municipality of Rio Branco $\left(10^{\circ} 1^{\prime} 59.53^{\prime \prime} \mathrm{S}, 67^{\circ} 52^{\prime} 4.93^{\prime \prime} \mathrm{W}\right)$, and in the River Iaco, near the municipality of Sena Madureira $\left(9^{\circ} 04^{\prime} 18.35^{\prime \prime} \mathrm{S}, 68^{\circ} 39^{\prime} 12.56^{\prime \prime} \mathrm{W}\right)$, State of Acre (Brazil), from June 2015 to May 2017. Fish were kept alive in sterile water tanks until necropsy in the Laboratory of Aquiculture of the Instituto Federal de Educação, Ciências e Tecnologia do Acre (acronym IFAC). Host nomenclature and classification follow Froese \& Pauly (2019).

Gills were removed, immediately placed in vials containing hot water $\left(60^{\circ} \mathrm{C}\right)$, gently shaken and transferred to Petri dishes containing formaldehyde solution to a final concentration of $5 \%$. Parasites were collected with the aid of a thin probe under a stereomicroscope. In order, to study the sclerotised structures, some specimens were mounted in Gray and Wess medium and others were stained with Gomori's trichrome stain and mounted in Canada balsam for observation of the internal anatomy (Boeger \& Vianna, 2006). Observations using light microscopy, drawings, and measurements were made with the aid of a Leica DM 5500B microscope equipped with Nomarski interference contrast, a drawing tube attached and a camera Leica DFC495 with the software Leica LAS (version 4.0). Measurements, all in micrometers, represent straight-line distances, except for the male copulatory organ (MCO), between extreme points of the structures and are expressed as the range followed by the mean and number (n) of measured structures in parentheses. Numbering and distribution of hook pairs follow Mizelle \& Price (1963); orientation of the MCO coils, (i.e. counterclockwise or clockwise) was determined as suggested by Kritsky et al. (1985). Base on the results of Mendoza-Palmero et al. (2015), we refrain from using the subfamily hierarchy within the Dactylogyridae.

For comparative purposes the following specimens, deposited in the Coleção Helmintológica do Instituto Oswaldo Cruz (CHIOC), were examined: Ameloblastella paranaensis (França, Isaac, Pavanelli \& Takemoto, 2003) (referred to as Pseudovancleaveus paranaensis) (CHIOC 34588a, b and 34598b) and Demidospermus leptosynophallus Kritsky \& Gutierrez, 1998 (referred to as D. mandi) (CHIOC 34586b, 34587c, 34589, 34590, 34591, 34592, 34593a-b).

Type- and voucher specimens were deposited in the CHIOC and in the Coleção Zoológica da Universidade Federal de Mato Grosso do Sul (acronym ZUFMS). 


\section{Subclass Polyonchoinea Bychoswky, 1937 \\ Order Dactylogyridea Bychoswky, 1937 \\ Family Dactylogyridae Bychowsky, 1933 \\ Genus Ameloblastella Kritsky, Mendoza-Franco \\ \& Scholz, 2000}

\section{Ameloblastella amazonica $\mathbf{n}$. sp.}

Type-host: Pimelodus blochii Valenciennes (Siluriformes: Pimelodidae).

Type-locality: River Iaco $\left(9^{\circ} 04^{\prime} 18.35^{\prime \prime} \mathrm{S}\right.$, $\left.68^{\circ} 09^{\prime} 12.56^{\prime \prime} \mathrm{W}\right)$, municipality of Sena Madureira, State of Acre, Brazil.

Other locality: River Acre $\left(10^{\circ} 01^{\prime} 59.53^{\prime \prime} \mathrm{S}\right.$, $\left.67^{\circ} 52^{\prime} 4.93^{\prime \prime} \mathrm{W}\right)$, municipality of Rio Branco, State of Acre, Brazil.

Type-material: The holotype (CHIOC 40020a) and 4 paratypes (CHIOC 40020b-e) were submitted to the Coleção Helmintológica do Instituto Oswaldo Cruz. One paratype (ZUFMS-PLA00030) was submitted to the Coleção Zoológica da Universidade Federal de Mato Grosso do Sul.

Site on host: Gills.

Prevalence and abundance: Prevalence: 3.7\% (3 infected fish/80 examined in River Iaco); 32.5\% (26 infected fish/80 examined in River Acre). Mean abundance: $0.05 \pm 0.3$ (Iaco River); $1.1 \pm 3.8$ (River Acre).

Etymology: The specific epithet refers the macrorregion of the type locality.

\section{Description (Fig. 1)}

[Based on 14 specimens: 10 mounted in Gray and Wess medium and 4 stained with Gomori's trichrome.] Body 229-288 (265; $\mathrm{n}=10)$ long; greatest width 82-98 $(93 ; \mathrm{n}=10)$ at mid-level of germarium (Fig. 1A). Cephalic region rounded, with indistinct cephalic lobes and 3 pairs of head organs; cephalic glands not observed (Fig. 1A). Eye-spots absent. Pharynx subspherical, $23-30 \times 15-20 ;(27 \times 18)(n$ =9), followed by oesophagus, c.50 long (Fig. 1A). Haptor sub-hexagonal, 32-61 (38; $\mathrm{n}=5)$ long, 41-81 $(65 ; \mathrm{n}=5)$ wide (Fig. 1A). Anchors dissimilar in size and shape (Fig. 1B, C). Ventral anchors composed of well-developed superficial root, short deep root, straight shaft and point not passing level of superficial root tip, 31-33 (32; $\mathrm{n}=10)$ long (Fig. 1B). Dorsal anchors with well-developed superficial and deep roots, straight shaft and point slightly passing level of superficial root tip, 32-35 (33; $n=10)$ long (Fig. 1C). Ventral bar 42-52 (47; $\mathrm{n}=9)$ long, slightly curved, rounded in lateral ends, bearing posteromedial projection (Fig. 1D). Dorsal bar 47-63 (57; $\mathrm{n}=9)$ long, slightly U-shaped, rounded in lateral ends, with posteriorly directed flap arising from its anterior edge of middle third (Fig. 1E). Hooks dissimilar in size and similar in shape, composed of 2 subunits, shank with rounded proximal end, erect thumb and curved shaft ending in distal point (Fig. 1F-H). Hook pair 1, 13-15 $(14 ; \mathrm{n}=4)$ long (Fig. 1G); pairs 5, 8-13 $(9 ; \mathrm{n}=3)$ long (Fig. 1F); pairs 2-4, 6 and 7, 18-22 $(20 ; n=9)$ long (Fig. 1H). FH loop in all hooks about $10 \%$ of shank length (Figs. 1F-H). Male copulatory organ (MCO) coiled, with 3-4 counterclockwise rings, its small base articulated with accessory piece by medium-sized, thick, smooth, tubular structure; diameter of proximal ring 9-11 $(10 ; n=9)$ (Fig. 1I). Accessory piece 15-18 $(16 ; n=9)$ long, with ventral median groove serving as guide for part of MCO (Fig. 1I). Germarium, 100-125 $(111 ; \mathrm{n}=3)$ long, 20-50 (31; $\mathrm{n}=3)$ wide, ventrally overlapping testis (difficult to observe). Seminal receptacle subspherical, median, dorsally superposed to anterior end of germarium (Fig. 1A). Vagina opening on sinister margin of body at about its midlength, consisting of sinuous and poorly sclerotised thin tube (Fig. 1A). Seminal vesicle well-developed, subspherical and adjacent to pair of subspherical prostatic reservoirs dissimilar in size; all posterior to MCO. Vas deferens, oviduct, oötype and uterus not observed. Vitelline follicles dense, coextensive with caeca (Fig. 1A).

\section{Remarks}

The present specimens were allocated in the genus Ameloblastella mainly because of the absence of eyespots, the presence of a medial process in the ventral bar, the MCO is composed by counterclockwise rings and its base being articulated with the accessory piece (Kritsky et al., 2000). Although the testis was difficult to observe, it was possible to confirm that the organ dorsally overlaps the germarium, consequently agreeing with the generic diagnosis of Ameloblastella (see Kritsky et al., 2000).

The dorsal bar bearing one median flap is present only in the new species and in the most closely related congener A. paranaensis, a parasite of pimelodid 

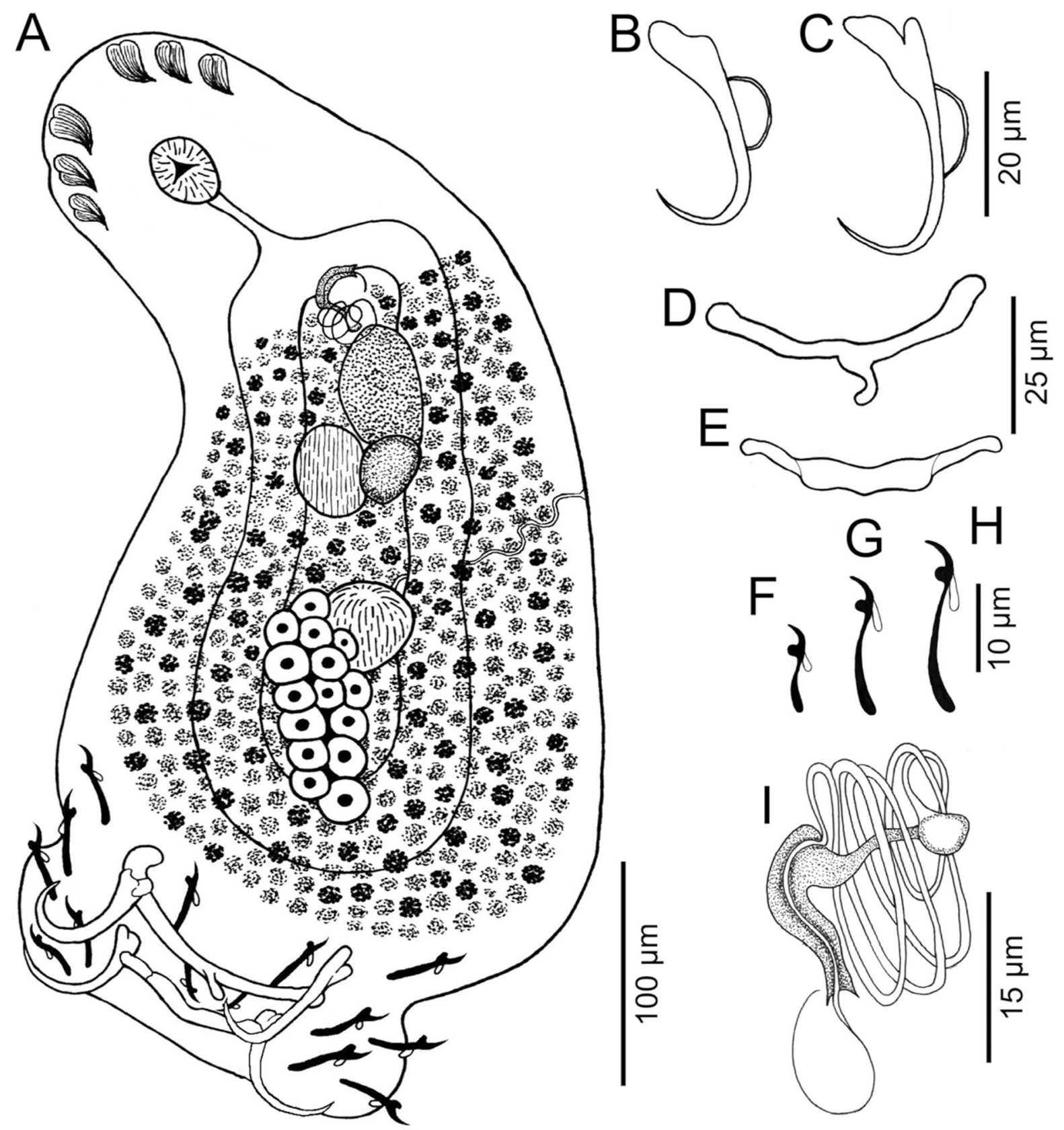

Fig. 1 Ameloblastella amazonica n. sp. ex Pimelodus blochii, collected in River Iaco, State of Acre, Brazil. Holotype. A, Whole mount (ventral view); B, Ventral anchor; C, Dorsal anchor; D, Ventral bar (ventral view); E, Dorsal bar (ventral view); F, Hook of pair 5; G, Hook of pair 1; H, Hook of pairs 2-4, 6 and 7; I, Copulatory complex (ventral view)

fishes from the Rivers Paraná and São Francisco, Brazil (França et al., 2003; Monteiro et al., 2010). However, A. amazonica n. sp. differs from A. paranaensis based on the shape of the dorsal bar (slightly U-shaped vs pronounced U-shaped), the origin of its flap (in the anterior edge $v s$ in the posterior edge) and by having hooks of three different sizes ( $v s$ all hooks of similar size) (see Monteiro et al., 2010). All these features were confirmed in A. paranensis after observation of the type-specimens (CHIOC 34588a, b; 34598b). Moreover, hooks with similar size were also described in A. chavarriai 
(Price, 1938), A. edentensis Mendoza-Franco, Mendoza-Palmero \& Scholz, 2016, A. mamaevi (Kritsky \& Thatcher, 1976), A. satoi Monteiro, Kritsky \& BrasilSato, 2010 and A. unapi Mendoza-Franco \& Scholz, 2009, and hooks with two different sizes were described in A. unapioides Mendoza-Franco, Mendoza-Palmero \& Scholz, 2016 and A. peruensis Mendoza-Franco, Mendoza-Palmero \& Scholz, 2016 (see Kritsky et al., 2000; Mendoza-Franco \& Scholz, 2009; Mendoza-Franco et al., 2016). However, all the above species differ from A. amazonica n. sp. based on the size of the hooks in addition to the dorsal bar structure. Although A. formatrium Mendoza-Franco, MendozaPalmero \& Scholz, 2016 and A. platensis (Suriano \& Incrovaia, 1995) are the only two congeners having hooks of three different sizes as in the new species, their dorsal bars lack the median flap and are V-shaped (Suriano \& Incrovaia, 1995; Kritsky et al., 2000; Mendoza-Franco et al., 2016) (vs slightly U-shaped bearing a median flap).

The MCO and the accessory piece also distinguish A. amazonica $\mathrm{n}$. sp. from the remaining congeners as follows. Ameloblastella chavarriai, A. formatrium, A. peruensis and A. unapi have 2.5, 2, 5.5 and 13-14 counterclockwise rings in the MCO, respectively ( $v s$ 3-4 in the new species) (Kritsky et al., 2000; Mendoza-Franco \& Scholz, 2009; Mendoza-Franco et al., 2016). The structure articulating the base of MCO with the accessory piece in A. paranaensis, A. peruensis, A. platensis, A. satoi and A. unapioides is thin and filamentous, in A. edentensis is a zig-zag tube, in A. formatrium is a very short thin tube and in A. unapi is a long tube bearing several small sclerotised spines, contrasting to A. amazonica $\mathrm{n}$. sp. that has a thick, medium-sized, smooth and tubular articulation between the MCO base and the accessory piece (Suriano \& Incrovaia, 1995; Kritsky et al., 2000; Mendoza-Franco \& Scholz, 2009; Monteiro et al., 2010; Mendoza-Franco et al., 2016). The accessory piece in A. chavarriai has two subunits $v s$ single in the new species (Kritsky et al., 2000).

The anchor points in A. amazonica n. sp. are at the same level or slightly passing the superficial root tip, differentiating it from A. formatrium, A. mamaevi, A. peruensis, A. satoi and A. unapioides that have at least one pair of anchors with points largely passing the level of the superficial root tip (Kritsky \& Thatcher, 1976; Monteiro et al., 2010; MendozaFranco et al., 2016).
In addition to $A$. amazonica n. sp., other two monogenean species were found infecting $P$. blochii in the present study, D. leptosynophallus (accession number ZUFMS-PLA00031) on the gills and S. yuncensi Jara \& Cone, 1989 (accession number ZUFMSPLA00029) on the body surface. The identity of D. leptosynophallus was confirmed after comparison with the specimens deposited in the CHIOC (CHIOC 34586b, 34587c, 34589, 34590, 34591, 34592, $34593 a-b)$. Unfortunately, we had no access to the types of $S$. yuncensi, but its original description has sufficient and clear morphological details (see Jara \& Cone, 1989) making it possible to confirm the specific status of the present specimens. The photomicrographs showing the diagnostic features of D. leptosynophallus and S. yuncensi, collected in the preset study are provided in the Supplementary Figures S1 and S2.

\section{Discussion}

Although the present specimens of $S$. yuncensi showed a lager body and longer anchors and bars, the morphology of all sclerotised structures along with the morphometry of hooks and MCO were highly similar when compared with the type-material (see Table 1 and Jara \& Cone, 1989). These differences may be accounted as intraspecific variation and are possibly a consequence of dissimilarities on host and parasite microhabitat attributes.

Since D. leptosynophallus and S. yuncensi have their diagnostic features well-represented in the literature (see Jara \& Cone, 1989; Kritsky \& Gutiérrez, 1998; França et al., 2003; Cohen \& Kohn, 2008), we refrain from describing and representing these species in detail, but a comparative table with their measurements and information regarding hosts and localities is given (see Table 1), as well as their diagnostic features are provided in photomicrographs in the Supplementary Figures S1 and S2.

Considering the high biodiversity potential of both fish and monogeneans in the Neotropical region, it is acceptable that our current knowledge on their species richness and host-parasite relationships is poor. An example is that the Pimelodidae, one of the endemic families of Siluriformes in the Neotropics, allocates 134 species with only 25 examined for monogeneans (Aguiar et al., 2017). The present results also illustrate this situation, in which D. leptosynophallus and 
Table 1 Host, geographical distribution (river, country) and the most important comparative measurements (as ranges in $\mu \mathrm{m})$ of Scleroductus yuncensi and Demidospermus leptosynophallus. The measurements are based on the newly collected specimens and those from the type-series. The type-host and type-locality are in bold

\begin{tabular}{|c|c|c|c|c|}
\hline & $\begin{array}{l}\text { Scleroductus } \\
\text { yuncensi } \\
(\mathrm{n}=6)\end{array}$ & $\begin{array}{l}\text { Scleroductus yuncensi } \\
(\mathrm{n}=6)\end{array}$ & $\begin{array}{l}\text { Demidospermus } \\
\text { leptosynophallus }(\mathrm{n}=10)\end{array}$ & $\begin{array}{l}\text { Demidospermus leptosynophallus } \\
(\mathrm{n}=16)\end{array}$ \\
\hline $\begin{array}{l}\text { Host: locality } \\
\text { (reference) }\end{array}$ & $\begin{array}{l}\text { Pimelodus } \\
\text { blochii }{ }^{\mathrm{a}} \text { : } \\
\text { Acre, } \\
\text { Brazil } \\
\text { (present } \\
\text { study) }\end{array}$ & $\begin{array}{l}\text { Pimelodella yuncensis }^{\mathrm{b}} \text { : } \\
\text { Chicama, Perú (Jara \& Cone, } \\
\text { 1989); Pimelodus albicans }{ }^{\mathrm{a}} \\
\text { and P. maculatus }{ }^{\mathrm{a}} \text { : La Plata, } \\
\text { Argentina (Gutiérrez \& } \\
\text { Martorelli, 1999a, b); } \\
\text { Leporinus copelandii } \text { : } \\
\text { Guandu, Brazil (Azevedo } \\
\text { et al., 2010) }\end{array}$ & $\begin{array}{l}\text { Pimelodus blochii: Acre, } \\
\text { Brazil (present study) }\end{array}$ & 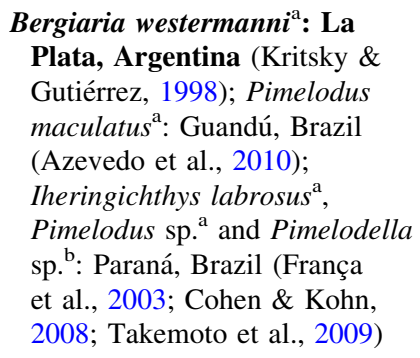 \\
\hline Body length & $440-667$ & $400-470^{\mathrm{d}}$ & $320-549$ & $405-648$ \\
\hline $\begin{array}{l}\text { Body } \\
\text { maximum } \\
\text { width }\end{array}$ & $93-163$ & $90^{\mathrm{d}}$ & $79-96$ & $122-163$ \\
\hline $\begin{array}{l}\text { Pharyngeal } \\
\text { bulb width }\end{array}$ & $35-42$ & $35-45^{\mathrm{d}}$ & $21-31$ & $34-40$ \\
\hline $\begin{array}{l}\text { Posterior } \\
\text { pharyngeal } \\
\text { bulb width }^{\mathrm{e}}\end{array}$ & $42-57$ & - & - & - \\
\hline $\begin{array}{l}\text { Testicle } \\
\text { length } \times \\
\text { width }\end{array}$ & $26-30$ & - & $40-65 \times 26-33$ & $71-103 \times 26-33$ \\
\hline $\begin{array}{l}\text { Germarium } \\
\text { length } \times \\
\text { width }\end{array}$ & $12-12$ & - & $37-56 \times 20-27$ & $38-57 \times 31-42$ \\
\hline MCO length ${ }^{f}$ & $12-16$ & $15-16^{\mathrm{d}}$ & $65-79$ & $75-95$ \\
\hline $\begin{array}{l}\text { Acessory } \\
\text { piece }\end{array}$ & - & - & $35-45$ & $62-65$ \\
\hline $\begin{array}{l}\text { Dorsal } \\
\text { anchors } \\
\text { length }\end{array}$ & $49-142$ & $75-78^{d}$ & $42-50$ & $35-41$ \\
\hline $\begin{array}{l}\text { Ventral } \\
\text { anchors } \\
\text { length }\end{array}$ & - & - & $58-63$ & $34-44$ \\
\hline $\begin{array}{l}\text { Dorsal bar } \\
\text { length }\end{array}$ & - & - & $57-76$ & $63-78$ \\
\hline $\begin{array}{l}\text { Ventral bar } \\
\text { length }^{\mathrm{g}}\end{array}$ & $14-40$ & $12-18^{\mathrm{d}}$ & $73-100$ & $80-90$ \\
\hline Hook length & $\begin{array}{l}19-22 \text { (all } \\
\text { similar) }\end{array}$ & $20-21^{\mathrm{d}}$ (all similar) & $\begin{array}{l}\text { pair 1: 38-41; pair 2: } \\
\text { 26-31; pair 3: 16-19; } \\
\text { pair 4: 15-19; pair 5: } \\
\text { 23-25; pair 6: 24-34; } \\
\text { pair 7: 40-43 }\end{array}$ & $\begin{array}{l}\text { pair 1: } 39-46 \text {; pair 2: } 31-33 \text {; pair } \\
\text { 3: 16-18; pair 4: } 16-18 \text {; pair 5: } \\
\text { 22-25; pair 6: 22-25; pair 7: } \\
\text { 39-46 }\end{array}$ \\
\hline
\end{tabular}

${ }^{\mathrm{a}}$ Pimelodidae; ${ }^{\mathrm{b}}$ Heptapteridae; ${ }^{\mathrm{c}}$ Anostomidae; ${ }^{\mathrm{d}}$ Measurements based on the type material; ${ }^{\mathrm{e}}$ Exclusive of Scleroductus; ${ }^{\mathrm{f}} \mathrm{Measured}$ as diameter in Scleroductus; ${ }^{\mathrm{g}}$ Corresponds to the superficial bar of Scleroductus 
S. yuncensi represent new host and locality records, being reported for the first time in the Brazilian Amazon.

The genus Ameloblastella includes host-specific species mostly infecting pimelodid fishes, and its geographical distribution ranges from South Mexico, Central and South America, extending to southern Brazil (Boeger \& Vianna, 2006; Aguiar et al., 2017). The new species represents the eleventh species in the genus, the third from Brazil and the first parasitising a pimelodid catfish from the Brazilian Amazon, thus improving our knowledge of the biodiversity aspects of this genus of ectoparasites.

It seems that, at least in some cases, the close relatedness between host taxa overshadows the influence of environment in the geographical distribution of some monogenean species (Braga et al., 2015). It can be noted for D. leptosynophallus and S. yuncensi, which infect mostly fishes belonging to the family Pimelodidae, also occur in the closely related Heptapteridae (Vergara et al., 2008) from different and unconnected river basins (see Table 1). It should be mentioned that the report of $S$. yuncensi infecting Leporinus coperlandii Steindachner (Characiformes: Anostoidae) (Azevedo et al., 2010), may represent a misidentification because the parasite seems to be specific to catfishes (Siluriformes). However, we had no response from the collection were the vouchers have been deposited (Coleção Helmintológica do Instituto de Biociências de Botucatú, accession number CHIBB 036L) and thus could not confirm the identification of this material.

Acknowledgements The authors would like to thank Drs Marcelo Knoff and Daniela A. Lopes, Coleção Helmintológica do Instituto Oswaldo Cruz (CHIOC), for the loan of specimens and André Mota for preparing the line drawings. Thanks are also due to Dr Marcus Vinícius Domingues, Universidade Federal do Pará (Brazil), for the critical comments regarding some aspects of the study.

Funding This study was financed in part by the Coordenação de Aperfeiçoamento de Pessoal de Nível Superior-Brasil (CAPES)-Finance code 001. FBP was supported by a Postdoctoral fellowship PNPD-CAPES (Programa Nacional de PósDoutorado-Coordenação de Aperfeiçoamento de Pessoal de Nível Superior-CAPES, Brazil). Marcos Tavares-Dias was granted (\# 303013/2015-0) a Research Fellowship from the National Council for Scientific and Technological Development (CNPq, Brazil).

\section{Compliance with ethical standards}

Conflict of interest The authors declare that they have no conflict of interest.

Ethical approval All procedures involving animals were permitted and were strictly according to the rules of the Sistema de Autorização e Informação em Biodiversidade (acronym SISBIO, No. 60899-1) and the Committee on Ethics of Animal Experiments of the Embrapa Amapá (Protocol No. 002- CEUACPAFAP).

\section{References}

Acosta, A. A., Scholz, T., Blasco-Costa, I., Alves, P. V., \& Silva, R. J. (2017). A new genus and two new species of dactylogyrid monogeneans from gills of Neotropical catfishes (Siluriformes: Doradidae and Loricariidae). Parasitology International, 67, 4-12.

Aguiar, J. C., Maia, A. A. M., Silva, M. R. M., Ceccarelli, P. S., Domingues, M. V., \& Adriano, E. A. (2017). An integrative taxonomic study of Pavanelliella spp. (Monogenoidea, Dactylogyridae) with the description of a new species from the nasal cavities of an Amazon pimelodid catfish. Parasitology International, 66, 777-788.

Azevedo, R. K., Abdallah, V. D., José, L., \& Luque, J. L. (2010). Acanthocephala, Annelida, Arthropoda, Myxozoa, Nematoda and Platyhelminthes parasites of fishes from the Guandu river, Rio de Janeiro, Brazil. Check List, 6, 659-667.

Boeger, W. A., \& Vianna, R. T. (2006). Monogenoidea. In: Thatcher, V. E. (Ed.), Amazon fish parasites. Sofia: Pensoft Publishers, pp. 42-116.

Braga, M. P., Razzolini, E., \& Boeger, W. (2015). Drivers of parasite sharing among Neotropical freshwater fishes. Journal of Animal Ecology, 84, 487-497.

Cohen, S. C., \& Kohn, A. (2008). New data on species of Demidospermus (Dactylogyridae: Monogenea) parasitizing fishes from the reservoir Itaipu hydroelectric power station, Parana State, Brazil, with new synonymies. Brazilian Journal of Veterinary Parasitology, 17, 167-170.

Cohen, S. C., Kohn, A., \& Justos, M. C. N. (2013). South American monogenoidea parasites of fishes, amphibians and reptiles. Rio de Janeiro: Oficina de Livros, 659 pp.

França, J. G., Isaac, A., Pavanelli, G. C., \& Takemoto, R. M. (2003). Dactylogyridae (Monogenea) from the gills of Iheringichthys labrosus (Osteichthyes: Pimelodidae) from the upper Paraná River floodplain, Brazil, with the proposal of Pseudovancleaveus n. g. Systematic Parasitology, 54, 25-31.

Franceschini, L., Zago, A. C., Mülle, M. I., Francisco, C. J., Takemoto, R. M., \& Silva, R. J. (2018). Morphology and molecular characterization of Demidospermus spirophallus n. sp., D. prolixus n. sp. (Monogenea: Dactylogyridae) and a redescription of $D$. anus in siluriform catfish from Brazil. Journal of Helminthology, 91, 1-16. 
Froese R., \& Pauly, D. (Eds) (2019). FishBase. World Wide Web electronic publication. http://www.fishbase.org, version 02/2019.

Gutiérrez, P. A., \& Martorelli, S. R. (1999a). The structure of the monogenean community on the gills of Pimelodus maculatus from Río de la Plata (Argentina). Parasitology, 119, 177-182.

Gutiérrez, P. A., \& Martorelli, S. R. (1999b). Niche preferences and spatial distribution of Monogenea on the gills of Pimelodus maculatus in Río de la Plata (Argentina). Parasitology, 119, 183-188.

Hechinger, R. F., \& Lafferty, K. D. (2005). Host biodiversity begets parasite biodiversity: Bird final hosts and trematodes in snail intermediate hosts. Proceedings of the Royal Societey B, 272(1567), 1059-1066.

Jara, C. A., \& Cone, D. K. (1989). Scleroductus yuncensi gen. et sp. n. (Monogenea) from Pimelodella yuncensi (Siluriformes: Pimelodidae) in Peru. Proceedings of Helminthological Society of Washington, 56, 125-127.

Kritsky, D. C., Boeger, W. A., Mendoza-Franco, E. F., \& Vianna, R. T. (2013). Neotropical Monogenoidea. 57. Revision and phylogenetic position of Scleroductus Jara \& Cone, 1989 (Gyrodactylidae), with descriptions of new species from the Guatemalan chulin Rhamdia guatemalensis (Günther) (Siluriformes: Heptapteridae) in Mexico and the barred sorubim Pseudoplatystoma fasciatum (Linnaeus) (Siluriformes: Pimelodidae) in Brazil. Systematic Parasitology, 84, 1-15.

Kritsky, D. C., \& Gutiérrez, P. A. (1998). Neotropical Monogenoidea. 34. Species of Demidospermus (Dactylogyridae, Ancyrocephalinae) from the gills of pimelodids (Teleostei, Siluriformes) in Argentina. Proceedings of the Helminthological Society Washington, 65, 129-134.

Kritsky, D. C., Mendoza-Franco, E. F., \& Scholz, T. (2000). Neotropical Monogenoidea. 36. Dactylogyrids from the gills of Rhamdia guatemalensis (Siluriformes: Pimelodidae) from cenotes of the Yucatan Peninsula, Mexico with proposal of Ameloblastella gen. n. and Aphanoblastella gen. n. (Dactylogyridae, Ancyrocephalinae). Comparative Parasitology, 67, 76-84.

Kritsky, D. C., \& Thatcher, V. E. (1976). New monogenetic trematodes from freshwater fishes of western Colombia with the proposal of Anacanthoroides gen. n. (Dactylogyridae). Proceedings of the Helminthological Society of Washington, 43, 129-134.

Kritsky, D. C., Thatcher, V. E., \& Boeger, W. A. (1985). Neotropical Monogenea. 8. Revision of Urocleidoides (Dactylogyridae, Ancyrocephalinae). Proceedings of the Helminthological Society Washington, 53, 1-37.
Mendoza-Franco, E. F., Mendoza-Palmero, C. A., \& Scholz, T. (2016). New species of Ameloblastella Kritsky, MendozaFranco \& Scholz, 2000 and Cosmetocleithrum Kritsky, Thatcher \& Boeger, 1986 (Monogenea: Dactylogyridae) infecting the gills of catfishes (Siluriformes) from the Peruvian Amazonia. Systematic Parasitology, 93, 847-862.

Mendoza-Franco, E. F., \& Scholz, T. (2009). New dactylogyrids (Monogenea) parasitizing the gills of catfishes (Siluriformes) from the Amazon River basin in Peru. Journal of Parasitology, 95, 865-870.

Mendoza-Palmero, C. A., Blasco-Costa, I., \& Scholz, T. (2015). Molecular phylogeny of Neotropical monogeneans (Platyhelminthes: Monogenea) from catfishes (Siluriformes). Parasites \& Vectors, 8, 164.

Mizelle, J. D., \& Price, C. E. (1963). Additional haptoral hooks in the genus Dactylogyrus. Journal of Parasitology, 49, 1028-1029.

Monteiro, C. M., Kritsky, D. C., \& Brasil-Sato, M. C. (2010). Neotropical Monogenoidea. 55. Dactylogyrids parasitizing the pintado-amarelo Pimelodus maculatus Lacépède (Actinopterygii: Pimelodidae) from the Rio Sao Francisco. Brazil. Systematic Parasitology, 76, 179-190.

Nelson, J. S., Grande, T. C., \& Wilson, M. V. H. (2016). Fishes of the world. 5th ed. Hoboken: John Wiley \& Sons, 752 pp.

Padial, J. S., Miralles, A., De La Riva, I., \& Vences, M. (2010). The integrative future of taxonomy. Frontiers in Zoology, 7, 2-14.

Poulin, R. (2014). Parasite biodiversity revisited. International Journal for Parasitology, 44, 581-589.

Suriano, D. M., \& Incorvaia, I. S. (1995). Ancyrocephalid (Monogenea) parasites from siluriform fishes from Paranean-Platean ichthyogeographical province in Argentina. Acta Parasitologica, 40, 113-124.

Takemoto, R. M., Pavanelli, G. C., Lizama, M. A. P., Lacerda, A. C. F., Yamada, F. H., Moreira, L. H. A., et al. (2009). Diversity of parasites of fish from the Upper Paraná River floodplain, Brazil. Brazilian Journal of Biology, 69, 691-705.

Vergara, J., Azpelicuete, M. M., \& Garcia, G. (2008). Phylogeography of the Neotropical catfish Pimelodus albicans (Siluriformes: Pimelodidae) from río de la Plata basin, South America, and conservation remarks. Neotropical Ichthyology, 6, 75-85.

Publisher's Note Springer Nature remains neutral with regard to jurisdictional claims in published maps and institutional affiliations. 